- Original Paper •

\title{
Reduced Sensitivity of Tropical Cyclone Intensity and Size to Sea Surface Temperature in a Radiative-Convective Equilibrium Environment
}

\author{
Shuai WANG ${ }^{1,2}$ and Ralf TOUMI ${ }^{* 2}$ \\ ${ }^{1}$ State Key Laboratory of Satellite Ocean Environment Dynamics, Second Institute of Oceanography, Hangzhou 310000, China \\ ${ }^{2}$ Space and Atmospheric Physics Group, Department of Physics, Imperial College London, London SW7 2AZ UK
}

(Received 1 November 2017; revised 10 January 2018; accepted 29 January 2018)

\begin{abstract}
It has been challenging to project the tropical cyclone (TC) intensity, structure and destructive potential changes in a warming climate. Here, we compare the sensitivities of TC intensity, size and destructive potential to sea surface warming with and without a pre-storm atmospheric adjustment to an idealized state of Radiative-Convective Equilibrium (RCE). Without RCE, we find large responses of TC intensity, size and destructive potential to sea surface temperature (SST) changes, which is in line with some previous studies. However, in an environment under RCE, the TC size is almost insensitive to SST changes, and the sensitivity of intensity is also much reduced to $3 \%{ }^{\circ} \mathrm{C}^{-1}-4 \%{ }^{\circ} \mathrm{C}^{-1}$. Without the pre-storm RCE adjustment, the mean destructive potential measured by the integrated power dissipation increases by about $25 \%{ }^{\circ} \mathrm{C}^{-1}$ during the mature stage. However, in an environment under RCE, the sensitivity of destructive potential to sea surface warming does not change significantly. Further analyses show that the reduced response of TC intensity and size to sea surface warming under RCE can be explained by the reduced thermodynamic disequilibrium between the air boundary layer and the sea surface due to the RCE adjustment. When conducting regional-scale sea surface warming experiments for TC case studies, without any RCE adjustment the TC response is likely to be unrealistically exaggerated. The TC intensity-temperature sensitivity under RCE is very similar to those found in coupled climate model simulations. This suggests global mean intensity projections under climate change can be understood in terms of a thermodynamic response to temperature with only a minor contribution from any changes in large-scale dynamics.
\end{abstract}

Key words: tropical cyclone, sea surface temperature, radiative-convective equilibrium, intensity, size, destructive potential

Citation: Wang, S., and R. Toumi, 2018: Reduced sensitivity of tropical cyclone intensity and size to sea surface temperature in a Radiative-Convective equilibrium environment. Adv. Atmos. Sci., 35(8), 981-993, https://doi.org/10.1007/s00376-0187277-5.

\section{Introduction}

Tropical cyclones (TCs) are one of the major natural hazards threatening human lives and properties in coastal regions. Although the understanding of TC dynamics and thermodynamics has been much advanced in recent decades (e.g., Emanuel, 1991, 1999a; Chan, 2005; Montgomery and Smith, 2017), it remains challenging to project TC features in a future warming climate (Vecchi et al., 2008; Bender et al., 2010; Knutson et al., 2010; Walsh et al., 2016).

Based on the established TC thermodynamic theories (Emanuel, 1986, 1995, 2003, 2007; Holland, 1997; Xu and Wang, 2010), TC intensity and size are closely related to sea surface temperature (SST). To investigate the response of TC intensity and structure to future sea surface warming, there are two commonly used numerical approaches in idealized and real TC case studies, which will be briefly reviewed

\footnotetext{
* Corresponding author: Ralf TOUMI

Email: toumi@imperial.ac.uk
}

below.

As the first approach to understanding the impact of SST on TC intensity and size, SST is changed whereas the initial atmospheric state is held. For example, Lau et al. (2016) found that with the present atmospheric state and a future SST pattern under a double carbon dioxide $\left(\mathrm{CO}_{2}\right)$ condition, the maximum hourly Power Dissipation Index (Emanuel, 2005) of Hurricane Sandy (2012) was more than doubled and the lifetime maximum area measured by the gale-force wind $\left(18 \mathrm{~m} \mathrm{~s}^{-1}\right)$ could be even tripled. Similar results regarding the intensity and size changes are also found in the case studies by Sun et al. (2017), who modified the present SST with a uniform increase and based on climate model projections. In this approach, TC intensity and size are highly sensitive to sea surface warming.

The second numerical approach is that of starting the TC simulation in the Radiative-Convective Equilibrium (RCE) state, adjusted to various SSTs. Nolan et al. (2007) showed that the RCE state adjusted to a high SST value is more favorable for TC genesis and intensification. However, they found 
that the lifetime maximum surface wind increased from about $55 \mathrm{~m} \mathrm{~s}^{-1}$ for SST $=25^{\circ} \mathrm{C}$ to about $65 \mathrm{~m} \mathrm{~s}^{-1}$ for SST $=30^{\circ} \mathrm{C}-$ a change of only about $2 \%{ }^{\circ} \mathrm{C}^{-1}$. They explained the low sensitivity using the maximum potential intensity $\left(V_{\text {pot }}\right)$ theory (Emanuel, 1986, 1995). However, they did not explore further to find out which term in the $V_{\text {pot }}$ calculation leads to the relatively low sensitivity of intensity to SST under RCE. The sensitivity of TC size to SST under RCE remains unexplored. Chavas and Emanuel (2014) showed that the wind speed of the whole azimuthal gradient wind profile increased under RCE from low to high SSTs. However, this positive relationship between SST and size was established based on the statistical equilibrium state of cyclones for simulation day 6090 , which is an unrealistically long period for real TCs to achieve.

Based on previous studies, TCs show quite different sensitivities of intensity to SST changes with and without a prestorm RCE adjustment. In addition, the size response to SST under RCE within a duration comparable to real TCs remains unclear. We will try to address these two problems in this study using the $V_{\text {pot }}$ theory (Emanuel, 1995), an analytic TC wind profile model [the $\lambda$ model (Wang et al., 2015)], and full-physics idealized numerical simulations with the Advanced Research Weather Research and Forecasting model (Skamarock et al., 2008).

Two main hypotheses will be tested:

(1) Compared to the simulations without the pre-storm RCE adjustment, the pre-storm RCE adjustment reduces the degree of thermodynamic disequilibrium between the air boundary layer and the sea surface, which leads to less sensitivity of both intensity and size to sea surface warming.

(2) The TC response to SST changes in coupled climate model projections is closer to the idealized simulations under RCE.

The next section introduces the model setup, experimental design, the $V_{\text {pot }}$ theory and the $\lambda$ model. The results are presented and discussed in sections 3 and 4. Section 5 summarizes our findings.

\section{Method}

\subsection{RCE adjustment}

For the pre-storm RCE adjustment, we conduct a highly idealized simulation with a square domain of $200 \mathrm{~km}(50 \times 50$ grid points), 41 vertical layers and grid spacing of $4 \mathrm{~km}$. The RCE adjustment is conducted over a water-only domain on an $f$-plane $\left(20^{\circ} \mathrm{N}, f \approx 5 \times 10^{-5} \mathrm{~s}^{-1}\right)$. Jordan's (1958) sounding is used as the initial condition and a doubly periodic lateral boundary condition is also applied. Each RCE adjustment lasts for 60 days with a time step of $30 \mathrm{~s}$. The domain setup follows Nolan et al. (2007) and Chavas and Emanuel (2014). Self-aggregation (Bretherton et al., 2005) does not appear in any RCE adjustment run.

All pre-storm RCE adjustment simulations use the following parameterization schemes: the Rapid Radiative Transfer Model scheme (Mlawer et al., 1997) and Dudhia
(1989) scheme to estimate the effect of longwave and shortwave radiation; the WSM six-class graupel scheme (Hong and Lim, 2006) for microphysical processes; the Yonsei University scheme (Hong and Lim, 2006) for parameterization processes in the planetary boundary layer; and the MM5 similarity scheme (Zhang and Anthes, 1982) for the surface layer simulation. We remove the diurnal cycle of shortwave radiation for RCE adjustment by keeping the solar zenith angle at $51.7^{\circ}$ and reducing the solar constant to $655 \mathrm{~W} \mathrm{~m}^{-2}$ (Tompkins and Craig, 1998a). The precise RCE state may vary with a different solar zenith angle and solar constant, but we will not discuss this in the current study. No cumulus scheme is used for RCE adjustments.

The criterion for RCE is that the potential temperature at each vertical layer below $200 \mathrm{hPa}$ does not change more than $1 \mathrm{~K}$ in the next 30 simulation days, which is a similar criterion as used in Chavas and Emanuel (2014). The duration to reach the RCE state may vary with different RCE definition criteria (Tompkins and Craig, 1998b). We take the 30-day mean and domain-averaged temperature and moisture vertical profiles after reaching the RCE state as the mean RCE sounding profile. With SST varying from $26^{\circ} \mathrm{C}-30^{\circ} \mathrm{C}$, all the RCE adjustments in this work are achieved within 20 simulation days. We therefore take the mean sounding from 20 to 50 simulation days as the sounding profiles in RCE.

An extra zonal wind $\left(U_{\text {sfc }}\right)$ is added into the surface layer scheme to increase the surface evaporation rate during the RCE adjustment. Nolan et al. (2007) showed that the RCE state mainly depends on two tuning variables, SST and $U_{\text {sfc }}$, and is insensitive to the Coriolis parameter. Chavas and Emanuel (2014) also found that if the tunable parameters in the radiation schemes are simply ignored, SST and $U_{\text {sfc }}$ are two main factors affecting the variation of RCE states. In this study, the influence of radiative processes on TCs under RCE will not be investigated. We next focus on SST and $U_{\text {sfc }}$ to design experiments.

\subsection{Experiment design}

Figure 1 shows the mean vertical structures of thermodynamic state for simulation days 20-50 with SST $=28^{\circ} \mathrm{C}$ and $U_{\mathrm{sfc}}=1$ or $5 \mathrm{~m} \mathrm{~s}^{-1}$. Due to a stronger surface evaporation rate with $U_{\text {sfc }}=5 \mathrm{~m} \mathrm{~s}^{-1}$, the boundary air is more saturated (Fig. 1d). High saturation of surface air leads to a weaker moisture contrast with the sea surface and hence a weaker environmental latent heat flux for the following cyclone simulations. As shown in Table 1, there are two groups of simulations in this study. In the first group, $U_{\mathrm{sfc}}$ is set as $1 \mathrm{~m} \mathrm{~s}^{-1}$, corresponding to a relatively high latent heat environment (named Group $\mathrm{HL}$ ). In the second group, $U_{\text {sfc }}$ is set as $5 \mathrm{~m} \mathrm{~s}^{-1}$, which simulates a relatively low latent heat environment (named Group LL).

In each group, we set SST $=28^{\circ} \mathrm{C}$ as the control. The control runs in both Group HL and Group LL reach the RCE after about 10 days. Based on the equilibrium states of the control runs, we conduct two sets of sensitivity experiments in each group. For Set HL_SST and LL_SST (the SST experiments), we change the SST and no further RCE adjustment is 

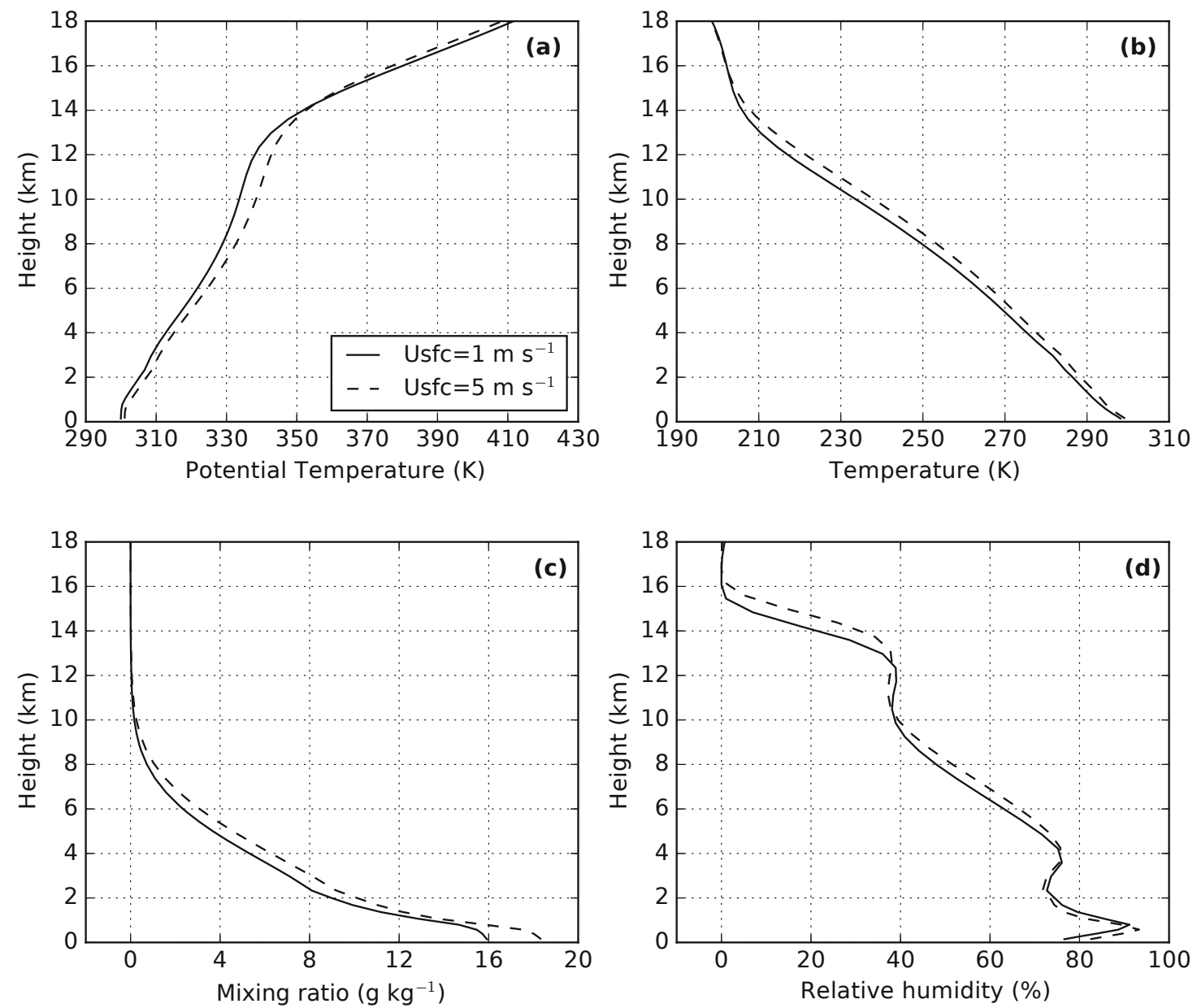

Fig. 1. Sounding profiles of (a) potential temperature (units: K), (b) temperature (units: K), (c) mixing ratio (units: $g$ $\mathrm{kg}^{-1}$ ) and (d) relative humidity (units: \%), averaged for simulation days 20-50 in the RCE adjustment runs with SST = $28^{\circ} \mathrm{C}$, and $U_{\text {sfc }}=1 \mathrm{~m} \mathrm{~s}^{-1}$ (solid line) or $5 \mathrm{~m} \mathrm{~s}^{-1}$ (dashed line). These two sounding profiles are used as "control runs" in this study.

Table 1. Experiment names and descriptions.

\begin{tabular}{|c|c|c|c|c|c|}
\hline \multirow[b]{2}{*}{$\begin{array}{l}\text { Group } \\
\text { name }\end{array}$} & \multirow[b]{2}{*}{ Set name } & \multirow[b]{2}{*}{$\begin{array}{l}\text { Simulation } \\
\text { name }\end{array}$} & \multicolumn{2}{|c|}{ Equilibrium run } & \multirow{2}{*}{$\begin{array}{c}\text { Cyclone run } \\
\text { SST } \\
\left({ }^{\circ} \mathrm{C}\right)\end{array}$} \\
\hline & & & $\begin{array}{c}U_{\text {sfc }} \\
\left(\mathrm{m} \mathrm{s}^{-1}\right)\end{array}$ & $\begin{array}{l}\text { SST } \\
\left({ }^{\circ} \mathrm{C}\right)\end{array}$ & \\
\hline \multirow[t]{9}{*}{ HL } & HL_CTL & HL_CTL28 & 1 & 28 & 28 \\
\hline & HL_SST & HL_SST26 & 1 & 28 & 26 \\
\hline & & HL_SST27 & 1 & 28 & 27 \\
\hline & & HL_SST29 & 1 & 28 & 29 \\
\hline & & HL_SST30 & 1 & 28 & 30 \\
\hline & HL_EQM & HL_EQM26 & 1 & 26 & 26 \\
\hline & & HL_EQM27 & 1 & 27 & 27 \\
\hline & & HL_EQM29 & 1 & 29 & 29 \\
\hline & & HL_EQM30 & 1 & 30 & 30 \\
\hline \multirow[t]{9}{*}{ LL } & LL_CTL & LL_CTL28 & 5 & 28 & 28 \\
\hline & LL_SST & LL_SST26 & 5 & 28 & 26 \\
\hline & & LL_SST27 & 5 & 28 & 27 \\
\hline & & LL_SST29 & 5 & 28 & 29 \\
\hline & & LL_SST30 & 5 & 28 & 30 \\
\hline & LL_EQM & LL_EQM26 & 5 & 26 & 26 \\
\hline & & LL_EQM27 & 5 & 27 & 27 \\
\hline & & LL_EQM29 & 5 & 29 & 29 \\
\hline & & LL_EQM30 & 5 & 30 & 30 \\
\hline
\end{tabular}

conducted. These experiments are designed to test the sensitivity of TC intensity and size to SST changes in the first approach, as reviewed in section 1. For HL_EQM and LL_EQM [the experiments after the equilibrium (EQM) adjustment], we change the SST and adjust the atmosphere to RCE again. The aim of these two sets of experiments is to test the sensitivity of TC intensity and size to SST changes under RCE, i.e., the second approach. We use domain-averaged temperature and moisture soundings for simulation days 20-50 to set up the environment for the TC simulations.

\subsection{TC simulation setup}

The initial field for the TC simulations is set up with different sounding profiles and an initial bogus vortex specified, as in Chan and Williams (1987), with the initial maximum surface wind, radius of maximum wind, and shape parameter $b$ set as $20 \mathrm{~m} \mathrm{~s}^{-1}, 75 \mathrm{~km}$ and 0.7 , respectively. Readers are referred to Wang et al. (2015) for more details on inserting the initial vortex and adjusting the thermal and dynamical fields.

The initial cyclone is on a spherical Earth at $20^{\circ} \mathrm{N}$ over an open ocean with a fixed SST. Two domains are nested with 
two-way interaction. There are 41 vertical layers in each domain. The outer square domain has sides of $9000 \mathrm{~km}$ and a grid spacing of $15 \mathrm{~km}$. The central latitude of the outer domain is $34^{\circ} \mathrm{N}$. The inner domain has sides of $2400 \mathrm{~km}$ and a grid spacing of $3 \mathrm{~km}$. The vortex-following technique is applied for the inner domain. The cyclone is tracked at $800 \mathrm{hPa}$. The time step for the outer and inner domains is $50 \mathrm{~s}$ and 10 s, respectively. Each cyclone simulation lasts for six days.

The lateral boundary condition of the inner domain is fed by the outer domain. The temperature and moisture at the lateral boundary of the outer domain is fixed as the initial sounding profile. A strong sponge layer with a width of 225 $\mathrm{km}$ is added along the lateral boundary of the outer domain. It is implemented by overwriting the horizontal wind speed in both directions to $0 \mathrm{~m} \mathrm{~s}^{-1}$ at all vertical levels and at every time step. The sponge layer reduces the noise level near the boundary so that the TC outer circulation (especially at the upper level) will not be influenced by artificial noise from the environment. At the start of the simulation, the cyclone is $3000 \mathrm{~km}$ away from the boundary. Although the circulation expands at the end of the simulation, the cyclone center is still at least $5000 \mathrm{~km}$ away from the outer boundary. The $\beta$-drift effect is included in the TC simulations but it will not be discussed in this study.

The parameterization schemes for the TC simulations are the same as for the RCE adjustments except that in the former an unmodified shortwave radiation with a diurnal cycle is used to create an Earth-like environment. There is no cumulus scheme in either domain. The inner domain with 3-km grid spacing is capable of resolving convective processes. To reduce the noise level in the surrounding area, the cumulus scheme is not included in the outer domain. Nevertheless, the convection related to the cyclone can still be reasonably simulated in the outer domain because of the two-way interaction and the large coverage of the inner domain.

\section{4. $V_{\text {pot }}$ and its factors}

$V_{\text {pot }}$ can be defined as (Emanuel, 1986, 1995)

$$
V_{\mathrm{pot}}=\sqrt{\frac{C_{K}}{C_{D}}\left(T_{\mathrm{s}}-T_{\mathrm{o}}\right) \frac{T_{\mathrm{s}}}{T_{\mathrm{o}}}\left(s^{*}-s\right)}
$$

where $C_{K}$ is the exchange coefficient for enthalpy, $C_{D}$ the drag coefficient, $T_{\mathrm{o}}$ the outflow temperature, $T_{\mathrm{s}}$ the SST under the eyewall, $s^{*}$ the saturation entropy of the sea surface, and $s$ the entropy of the boundary layer air. This expression is the dimensional equivalent of Eq. (13) in Emanuel (1995).

We can decompose the r.h.s. of Eq. (1) into three factors, i.e.,

$$
V_{\mathrm{pot}}=\sqrt{\frac{C_{K}}{C_{D}}\left(T_{\mathrm{s}}-T_{\mathrm{o}}\right) \frac{T_{\mathrm{s}}}{T_{\mathrm{o}}}\left(s^{*}-s\right)},
$$

where $C_{K}$ is the exchange coefficient for enthalpy, $C_{D}$ the drag coefficient, $T_{\mathrm{o}}$ the outflow temperature, $T_{\mathrm{S}}$ the SST under the eyewall, $s^{*}$ the saturation entropy of the sea surface, and $s$ the entropy of the boundary layer air. This expression is the dimensional equivalent of Eq. (13) in Emanuel (1995).
We can decompose the r.h.s. of Eq. (1) into three factors, i.e.,

$$
V_{\text {pot }}=\hat{C} \hat{T} \hat{S}
$$

where

$$
\begin{aligned}
& \hat{C}=\sqrt{\frac{C_{K}}{C_{D}}}, \\
& \hat{T}=\sqrt{\left(T_{\mathrm{s}}-T_{\mathrm{o}}\right) \frac{T_{\mathrm{s}}}{T_{\mathrm{o}}}}, \\
& \hat{S}=\sqrt{s^{*}-s} .
\end{aligned}
$$

The first factor, $\hat{C}$, represents the ratio of enthalpy to momentum exchange coefficients and will not be discussed in this study. For simplicity, we set this ratio as 0.9 in the following calculation, which lies in the range $0.75-1.5$ for real TCs (Emanuel, 1995). The second factor, $\hat{T}$, describes the vertical temperature contrast. Any change of $\hat{T}$ corresponds to the change of the efficiency of the cyclone energy cycle. The third factor, $\hat{S}$, can be interpreted as the degree of thermodynamic disequilibrium between the air boundary layer and the sea surface. Any change in $\hat{S}$ can result in different latent heat fluxes at the sea surface. We will show in the results section that the pre-storm RCE adjustment can change $\hat{T}$ and $\hat{S}$, and hence influence the cyclone intensity and size.

\subsection{Wind profile}

An analytic TC wind profile model, the $\lambda$ model (Wang et al., 2015), is used to provide a theoretical estimation of the wind profile changes due to sea surface warming. The $\lambda$ model can be written as

$$
V=\sqrt{\frac{2 \Delta p}{\rho}} \sqrt{\frac{0.56 R_{\mathrm{m}}^{2}}{r^{2}}\left(1-e^{-\frac{r^{2}}{0.56 R_{\mathrm{m}}^{2}}}\right)-e^{-\frac{r^{2}}{0.56 R_{\mathrm{m}}^{2}}}}-\frac{1}{2} f_{o} r
$$

where $V$ is the near-surface wind speed $\left(\mathrm{m} \mathrm{s}^{-1}\right) ; \Delta p$ is the pressure deficit $(\mathrm{Pa})$ between the cyclone center and the ambient environment; $\rho$ is the air density near the surface, which is set as $1.1 \mathrm{~kg} \mathrm{~m}^{-3} ; r$ is the radius $(\mathrm{m}) ; f_{o}$ is the Coriolis parameter, which is set as $5 \times 10^{-5} \mathrm{~s}^{-1}\left(20^{\circ} \mathrm{N}\right)$ in this study; and $R_{\mathrm{m}}$ is the radius of maximum wind (m).

The pressure deficit, $\Delta p$, in Eq. (6) is calculated with the surface maximum wind speed $\left(V_{\mathrm{m}}\right)$ and $R_{\mathrm{m}}$, according to a new wind-pressure relationship (Wang and Toumi, 2016, 2017):

$$
\Delta p=\rho\left(\frac{V_{\mathrm{m}}+0.5 f_{o} R_{\mathrm{m}}}{0.77}\right)^{2} .
$$

To estimate $R_{\mathrm{m}}$ in Eqs. (6) and (7), an empirical relationship used in operational forecasts is adopted (Knaff and Zehr, 2007; Courtney and Knaff, 2009), which can be written as

$$
R_{\mathrm{m}}=66785-176.92 V_{\mathrm{m}}+1061.9(\phi-25),
$$

where $\phi$ is the latitude of the cyclone center.

The TC destructive potential is measured by the integrated power dissipation (IPD; Emanuel, 1999b), which can be written as

$$
\mathrm{IPD}=\int_{S} \rho C_{D} V(r)^{3} d S,
$$


where the drag coefficient, $C_{D}$, is calculated with the wind speed (Large and Yeager, 2008); and $S$ is the integral area with the radius of gale-force wind $\left(R_{18}\right)$ at a height of 10 $\mathrm{m}$. The order of magnitude of IPD for a developed TC is typically about $10^{13} \mathrm{~W}$ (Emanuel, 1999b; Wang and Toumi, 2016).

\section{Results}

\subsection{Sensitivity based on theoretical models}

The $V_{\text {pot }}$ theory and the $\lambda$ model are used as theoretical tools to analyze the TC sensitivity to SST changes. As shown in Table 2, the sensitivity of $\hat{T}, \hat{S}$ and $V_{\text {pot }}$ are calculated with Eqs. (1)-(5), and the corresponding changes of $R_{18}$ and IPD are estimated with Eqs. (6)-(9).

First, Table 2 shows that the percentage change (\%) of $\hat{T}, \hat{S}, V_{\text {pot }}, R_{18}$ and IPD due to SST changes within a range of $26^{\circ} \mathrm{C}-30^{\circ} \mathrm{C}$ is almost linear in all four sets of experiments, which makes it possible to describe the sensitivities as " $\%{ }^{\circ} \mathrm{C}^{-1}$ " in the following analyses. Second, the sensitivity of $\hat{T}$ to SST changes are almost identical (about $1 \%{ }^{\circ} \mathrm{C}^{-1}$ $\left.2 \%{ }^{\circ} \mathrm{C}^{-1}\right)$ in all sets of experiments. In contrast, the sensitivity of $\hat{S}$ to SST changes depends strongly on the RCE adjustment. For example, the sensitivity of $\hat{S}$ in RCE is comparable to the sensitivity of $\hat{T}$, while the difference of the percentage change between $\hat{T}$ and $\hat{S}$ is much larger without RCE. Third, the sensitivities of $V_{\text {pot }}$ are about $12 \%{ }^{\circ} \mathrm{C}^{-1}$ and $16 \%{ }^{\circ} \mathrm{C}^{-1}$ without the pre-storm RCE, but only about $3 \%{ }^{\circ} \mathrm{C}^{-1}$ and $3 \%$ ${ }^{\circ} \mathrm{C}^{-1}$ in RCE. It is noteworthy that the intensity response to
SST changes under RCE is only about $20 \%$ of that in the environment without RCE.

Table 2 also shows that, like the intensity response, the size response to SST changes predicted by the $\lambda$ model is also much larger without RCE (about $7 \%{ }^{\circ} \mathrm{C}^{-1}$ and $11 \%{ }^{\circ} \mathrm{C}^{-1}$ ) than that in RCE (about $2 \%{ }^{\circ} \mathrm{C}^{-1}$ and $2 \%{ }^{\circ} \mathrm{C}^{-1}$ ). As a combined metric of intensity and size, IPD changes for $33 \%{ }^{\circ} \mathrm{C}^{-1}$ and $49 \%{ }^{\circ} \mathrm{C}^{-1}$ without RCE, and $9 \%{ }^{\circ} \mathrm{C}^{-1}$ and $8 \%{ }^{\circ} \mathrm{C}^{-1}$ in the RCE experiments. Table 2 suggests that the large difference of TC sensitivity to the same SST change can be attributed to the changes of $\hat{S}$ by RCE adjustments. We will return to this point later when analyzing the latent heat flux field in numerical simulations.

Figure 2 shows the wind profile changes predicted by the $\lambda$ model with various SST values. We can see that the wind profiles in the SST experiments change dramatically (Figs. 2a and $b$ ). Another important prediction by the $\lambda$ model is that, regardless of pre-storm RCE adjustments, the wind speed change is always larger in the inner core than the outer rainbands, which indicates a higher sensitivity of the inner core to the sea surface warming than the outer core.

Next, we will conduct full-physics idealized simulations to confirm the different sensitivities of intensity, size and destructive potential to SST changes as found in the theoretical calculations.

\subsection{Sensitivity based on idealized simulations}

The time series of the surface maximum wind speed, $V_{\mathrm{m}}$, in four sets of experiments is shown in Fig. 3. One can see

Table 2. Changes in $\hat{T}, \hat{S}$ and $V_{\text {pot }}$ in Eq. (2) based on $V_{\text {pot }}$ theory, and changes in $R_{18}$ and IPD calculated with the $\lambda$ model wind profiles.

\begin{tabular}{|c|c|c|c|c|c|c|c|c|c|c|}
\hline \multirow[b]{2}{*}{$\begin{array}{c}\text { Simulation } \\
\text { name }\end{array}$} & \multicolumn{2}{|c|}{$\hat{T}\left(\mathrm{~K}^{1 / 2}\right)$} & \multicolumn{2}{|c|}{$\hat{S}\left(\mathrm{~J}^{1 / 2} \mathrm{~K}^{-1 / 2} \mathrm{~kg}^{-1 / 2}\right)$} & \multicolumn{2}{|c|}{$V_{\text {pot }}\left(\mathrm{m} \mathrm{s}^{-1}\right)$} & \multicolumn{2}{|c|}{$R_{18}(\mathrm{~km})$} & \multicolumn{2}{|c|}{$\mathrm{IPD}\left(\times 10^{13} \mathrm{~W}\right)$} \\
\hline & $\begin{array}{c}\text { Absolute } \\
\text { value }\end{array}$ & $\begin{array}{c}\text { Percentage } \\
\text { change }\end{array}$ & $\begin{array}{c}\text { Absolute } \\
\text { value }\end{array}$ & $\begin{array}{c}\text { Percentage } \\
\text { change }\end{array}$ & $\begin{array}{l}\text { Absolute } \\
\text { value }\end{array}$ & $\begin{array}{c}\text { Percentage } \\
\text { change }\end{array}$ & $\begin{array}{c}\text { Absolute } \\
\text { value }\end{array}$ & $\begin{array}{c}\text { Percentage } \\
\text { change }\end{array}$ & $\begin{array}{c}\text { Absolute } \\
\text { value }\end{array}$ & $\begin{array}{c}\text { Percentage } \\
\text { change }\end{array}$ \\
\hline HL_SST26 & 11.9 & $-3 \%$ & 6.3 & $-22 \%$ & 57 & $-24 \%$ & 183 & $-15 \%$ & 1.3 & $-54 \%$ \\
\hline HL_SST27 & 12.1 & $-1 \%$ & 7.3 & $-11 \%$ & 67 & $-12 \%$ & 202 & $-6 \%$ & 2.0 & $-29 \%$ \\
\hline HL_CTL28 & 12.2 & $0 \%$ & 8.1 & $0 \%$ & 75 & $0 \%$ & 216 & $0 \%$ & 2.8 & $0 \%$ \\
\hline HL_SST29 & 12.4 & $2 \%$ & 9.0 & $10 \%$ & 84 & $12 \%$ & 230 & $6 \%$ & 3.8 & $36 \%$ \\
\hline HL_SST30 & 12.7 & $4 \%$ & 9.7 & $19 \%$ & 94 & $24 \%$ & 244 & $13 \%$ & 5.0 & $79 \%$ \\
\hline HL_EQM26 & 11.9 & $-3 \%$ & 7.9 & $-3 \%$ & 71 & $-6 \%$ & 209 & $-3 \%$ & 2.4 & $-14 \%$ \\
\hline HL_EQM27 & 12.0 & $-1 \%$ & 8.0 & $-2 \%$ & 73 & $-3 \%$ & 213 & $-1 \%$ & 2.6 & $-7 \%$ \\
\hline HL_CTL28 & 12.2 & $0 \%$ & 8.1 & $0 \%$ & 75 & $0 \%$ & 216 & $0 \%$ & 2.8 & $0 \%$ \\
\hline HL_EQM29 & 12.4 & $1 \%$ & 8.3 & $2 \%$ & 78 & $3 \%$ & 221 & $2 \%$ & 3.1 & $11 \%$ \\
\hline HL_EQM30 & 12.6 & $3 \%$ & 8.4 & $4 \%$ & 81 & $7 \%$ & 226 & $5 \%$ & 3.4 & $21 \%$ \\
\hline LL_SST26 & 11.8 & $-3 \%$ & 4.3 & $-35 \%$ & 39 & $-37 \%$ & 141 & $-27 \%$ & 0.4 & $-75 \%$ \\
\hline LL_SST27 & 12.0 & $-1 \%$ & 5.6 & $-16 \%$ & 51 & $-17 \%$ & 170 & $-12 \%$ & 0.9 & $-44 \%$ \\
\hline LL_CTL28 & 12.2 & $0 \%$ & 6.7 & $0 \%$ & 62 & $0 \%$ & 193 & $0 \%$ & 1.6 & $0 \%$ \\
\hline LL_SST29 & 12.4 & $2 \%$ & 7.6 & $15 \%$ & 72 & $16 \%$ & 211 & $9 \%$ & 2.5 & $56 \%$ \\
\hline LL_SST30 & 12.6 & $3 \%$ & 8.5 & $28 \%$ & 82 & $33 \%$ & 227 & $18 \%$ & 3.5 & $119 \%$ \\
\hline LL_EQM26 & 11.9 & $-3 \%$ & 6.5 & $-3 \%$ & 58 & $-5 \%$ & 185 & $-4 \%$ & 1.3 & $-19 \%$ \\
\hline LL_EQM27 & 12.1 & $-1 \%$ & 6.6 & $-1 \%$ & 60 & $-3 \%$ & 189 & $-2 \%$ & 1.5 & $-6 \%$ \\
\hline LL_CTL28 & 12.2 & $0 \%$ & 6.7 & $0 \%$ & 62 & $0 \%$ & 193 & $0 \%$ & 1.6 & $0 \%$ \\
\hline LL_EQM29 & 12.4 & $1 \%$ & 6.7 & $1 \%$ & 63 & $3 \%$ & 195 & $1 \%$ & 1.7 & $6 \%$ \\
\hline LL_EQM30 & 12.6 & $3 \%$ & 6.8 & $3 \%$ & 65 & $6 \%$ & 199 & $3 \%$ & 1.9 & $19 \%$ \\
\hline
\end{tabular}



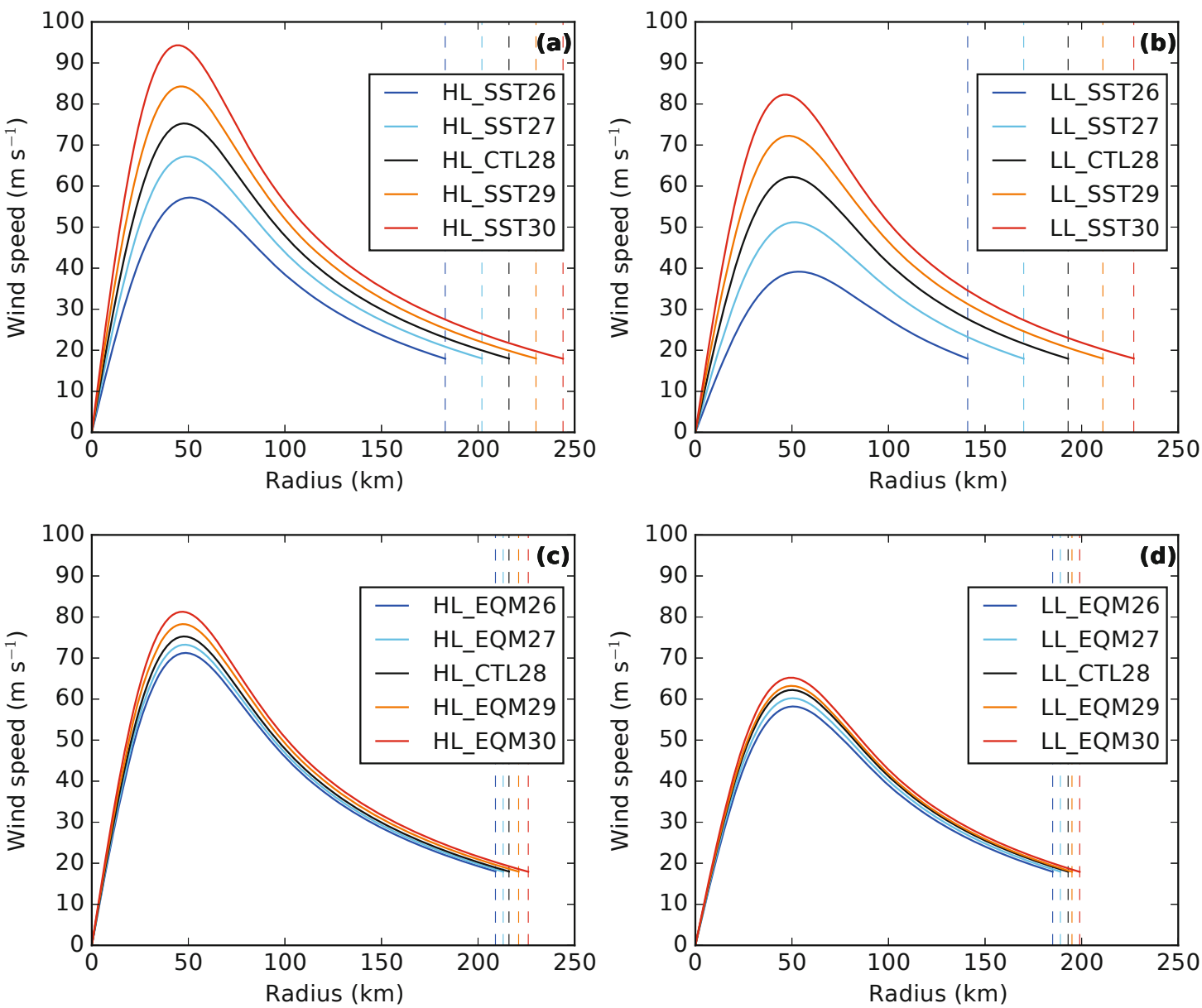

Fig. 2. Wind profiles predicted by the $\lambda$ model for set (a) HL_SST, (b) LL_SST, (c) HL_EQM and (d) LL_EQM. The wind profiles are shown up to $R_{18}$. The dashed lines show $R_{18}$.

that the intensity increases dramatically in the first two simulation days. From simulation hour 48 the intensity fluctuates around some mean value. We therefore identify the first two simulation days as the developing stage, and from simulation hour 48 the simulated cyclone reaches the mature stage.

There are two main findings from Fig. 3. First, as expected, the environment with high latent heat flux favors TC intensification. However, the average intensity difference between high and low latent heat flux environments is small. For example, the mean intensity in HL_CTL28 (Figs. 3a and c) during the mature stage is only about $1 \mathrm{~m} \mathrm{~s}^{-1}$ higher than LL_CTL28 (Figs. 3b and d). Second, compared to the sets with the pre-storm RCE adjustment (Figs. $3 \mathrm{c}$ and d), the TC intensity without the pre-storm RCE adjustment is more sensitive to SST changes (Figs. 3a and b). As shown in Table 3 , for example, in a high latent heat flux environment, the sensitivity of $\mathrm{TC}$ intensity decreases from $6.5 \%{ }^{\circ} \mathrm{C}^{-1}$ (set HL_SST) to $3.6 \%{ }^{\circ} \mathrm{C}^{-1}$ (set HL_EQM) if a pre-storm RCE is achieved.

Figure 4 shows the size changes in all four sets of experiments, which are similar to the intensity response shown in Fig. 3. Firstly, the cyclone can achieve a large size in a high latent heat flux environment. For instance, $R_{18}$ in HL_CTL28 is $450 \mathrm{~km}$ at simulation hour 144, whereas it is $70 \mathrm{~km}$ lower in
Table 3. Sensitivity $\left(\%{ }^{\circ} \mathrm{C}^{-1}\right)$ of intensity, size and destructive potential based on theoretical predictions and numerical simulations. If the change based on numerical simulations is in bold, it means that all four sensitivity experiments in one set is significantly different from the control run at the $95 \%$ confidence level based on the Student's $t$-test.

$$
V_{m}\left(\%{ }^{\circ} \mathrm{C}^{-1}\right) \quad R_{18}\left(\%{ }^{\circ} \mathrm{C}^{-1}\right) \quad \operatorname{IPD}\left(\%{ }^{\circ} \mathrm{C}^{-1}\right)
$$

Set name Theory Simulation Theory Simulation Theory Simulation

\begin{tabular}{lrrrrrr}
\hline HL_SST & 12.0 & $\mathbf{6 . 5}$ & 6.5 & $\mathbf{9 . 8}$ & 32.9 & $\mathbf{2 6 . 6}$ \\
HL_EQM & 3.1 & $\mathbf{3 . 6}$ & 1.8 & -0.3 & 8.9 & 4.3 \\
LL_SST & 17.0 & $\mathbf{7 . 3}$ & 10.9 & $\mathbf{1 2 . 6}$ & 49.3 & $\mathbf{2 7 . 9}$ \\
LL_EQM & 2.9 & $\mathbf{3 . 3}$ & 1.6 & -1.6 & 7.8 & 2.8 \\
\hline
\end{tabular}

LL_CTL28. Secondly, $R_{18}$ is very sensitive to SST changes if the environment is not adjusted to RCE (Figs. 4a and b). Table 3 shows that the percentage change of $R_{18}$ in set HL_SST (Fig. 4a) and LL_SST (Fig. 4b) is about $10 \%{ }^{\circ} \mathrm{C}^{-1}$. However, $R_{18}$ is almost insensitive to SST changes under RCE (Figs. 4c and $\mathrm{d}$ ).

The mean wind profile for simulation hours $48-144$ is shown in Fig. 5. Without a pre-storm RCE adjustment, the wind speed of the whole profile increases with increasing 

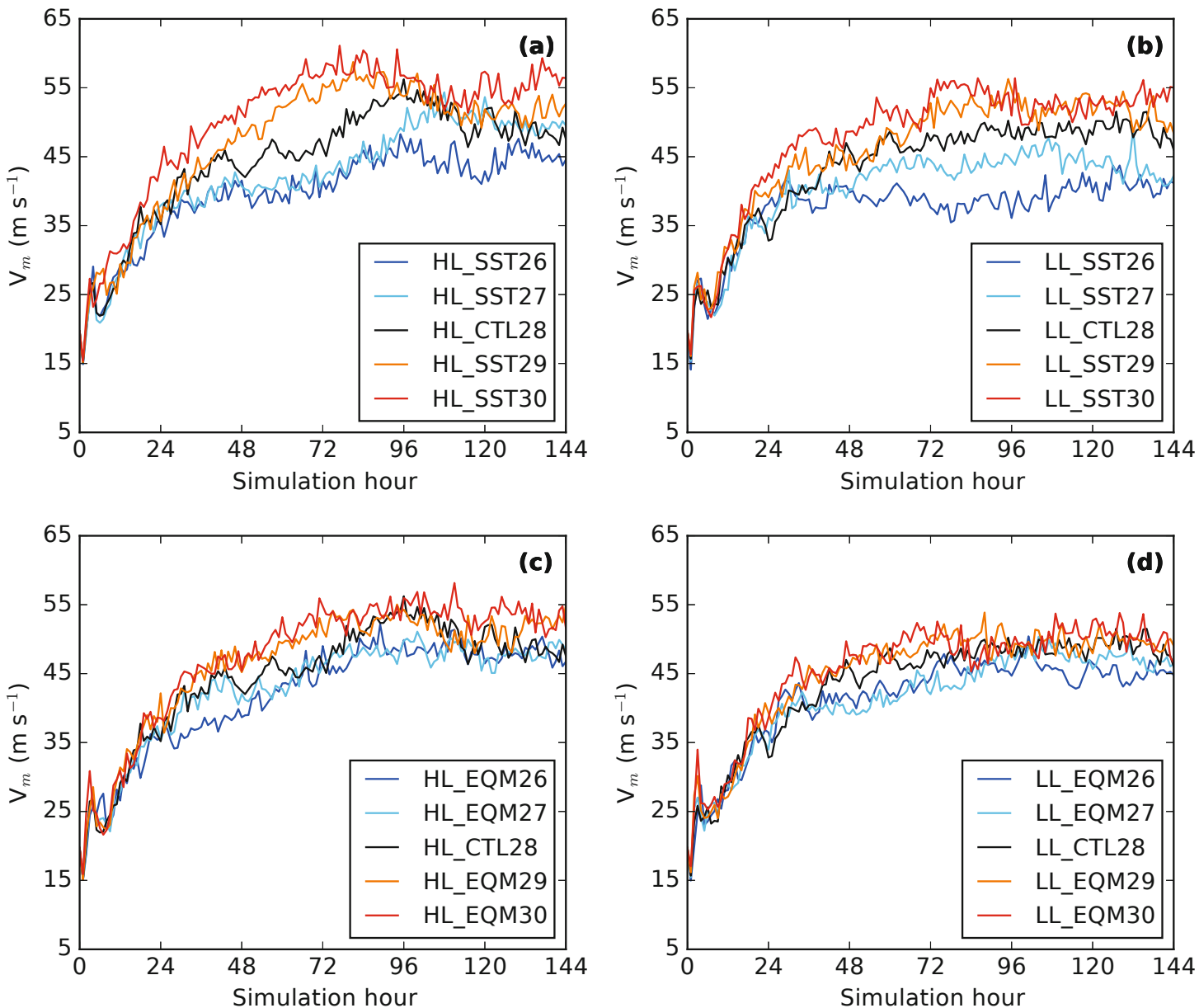

Fig. 3. Time series of simulated 10-m maximum wind (units: $\mathrm{m} \mathrm{s}^{-1}$ ) in set (a) HL_SST, (b) LL_SST, (c) HL_EQM and (d) LL_EQM.

SST (Figs. 5a and b). In contrast, if the environment is equilibrated, the changes of wind speed mainly happen in the inner core near the eyewall (Figs. 5c and d). These two main findings are qualitatively consistent with the prediction by the $\lambda$ model (Fig. 2), but the absolute sensitivity in the idealized numerical simulations is smaller than the theoretical prediction.

Figure 6 shows the time series of percentage change in the destructive potential measured by IPD. Due to the high sensitivity of intensity and size in the SST experiments, the percentage change of IPD in these two sets is evidently larger than for RCE. Table 3 shows that without the RCE adjustment, SST can significantly change the IPD with a rate of more than $25 \%{ }^{\circ} \mathrm{C}^{-1}$. On the other hand, if the environment is adjusted to RCE, sea surface warming may still increase the IPD through TC intensification. However, the change of IPD in RCE is not significant.

Table 3 compares the theoretical prediction and numerical simulation regarding the sensitivity of intensity, size and destructive potential. Firstly, we can see that the theoretical and simulated sensitivities of TC intensity are similar under RCE. Secondly, without the pre-storm RCE adjustment, TC size is more sensitive in the simulations than the $\lambda$ model prediction.
Thirdly, regardless of RCE adjustment, the sensitivity of IPD is always less in simulations than theoretically. Table 3 shows that, according to our idealized numerical simulations, only the TC intensity is significantly sensitive to SST changes under RCE. Although the IPD increases with high SSTs in the simulations, this is not found to be significant.

\subsection{Sensitivity and latent heat flux}

As shown in Table 2, factor $\hat{S}$ may be the main reason that TCs show different sensitivities to SST changes with and without the pre-storm RCE adjustment. Factor $\hat{S}$ can be interpreted as the degree of thermodynamic disequilibrium between the air boundary layer and the sea surface. High $\hat{S}$ values indicate strong latent heat fluxes from the sea surface. We therefore hypothesized in section 1 that different sensitivities of intensity and size with and without pre-storm RCE adjustments are caused by different latent heat fluxes.

To examine this hypothesis, the latent heat fluxes at simulation hour 72 is shown in Fig. 7. It is found that, regardless of RCE adjustment, the surface latent flux in the inner core is always stronger if SST is higher. Strong latent heat flux under the eyewall can contribute to high intensity. This explains why the intensity is significantly sensitive to SST changes in 

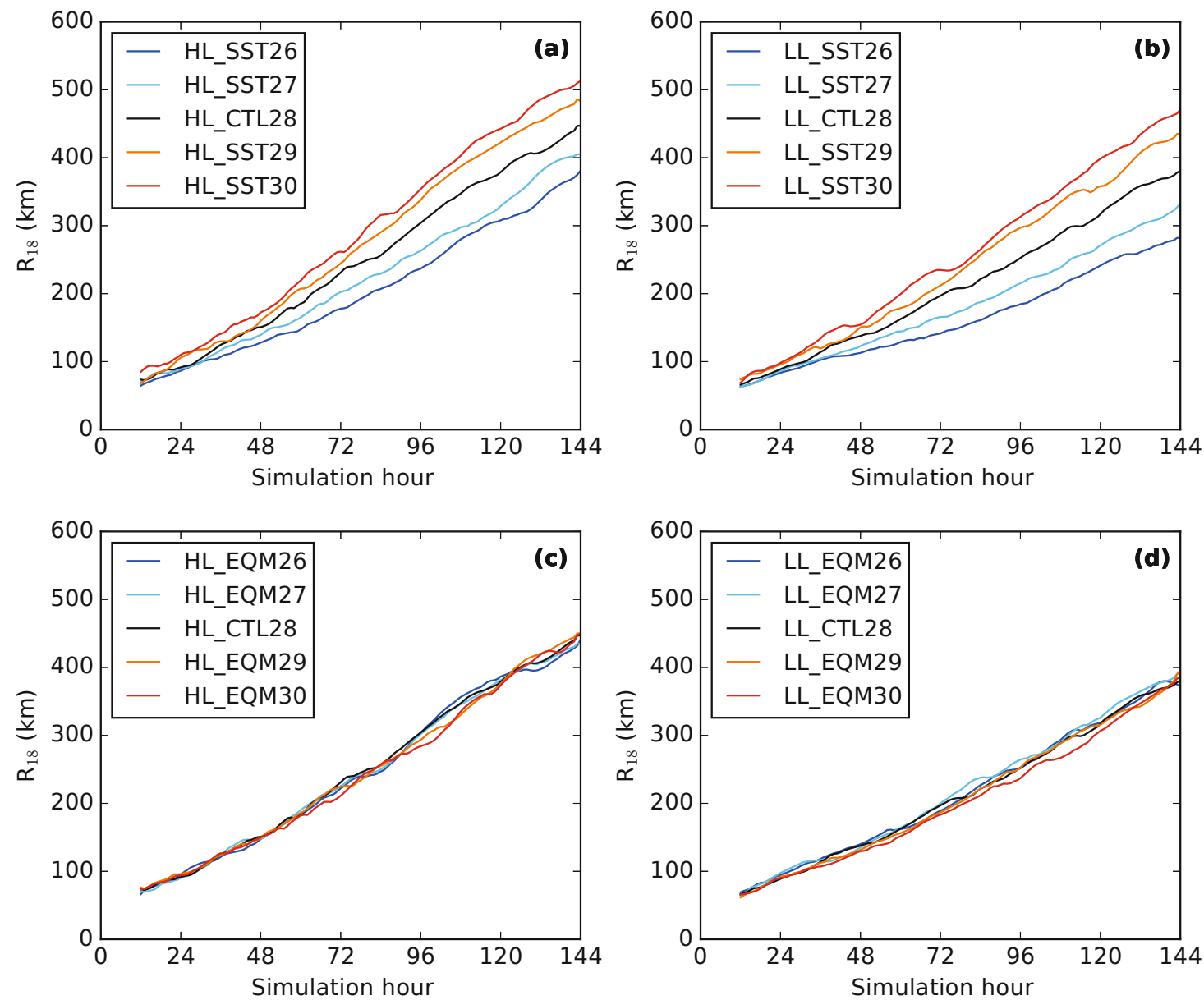

Fig. 4. As in Fig. 3 but for $R_{18}$ calculated with the azimuthally averaged 10-m wind profiles.

all four sets of experiments (Table 3). Secondly, without the RCE adjustment (Figs. 7a, b, e and f), the latent heat flux is much stronger around the area of gale-force wind in high SST runs than low SST runs. The large size difference is due to this large latent heat flux difference in the outer rainbands. Thirdly, under RCE (Figs. 7c, d, g and h), the influence of SST on the local latent heat flux around the area of gale-force wind is much less than the cases without the REC adjustment. This may explain why TC size is less sensitive to SST change for the cases under RCE.

\section{Discussion}

In this study, we use two factors, $\hat{T}$ and $\hat{S}$, to quantify the theoretical impact of sea surface warming on TC intensity and size under RCE. We find that, compared to the TC sensitivity without the pre-storm RCE adjustment, TC intensity and size show much lower sensitivity to the same sea surface warming under RCE. The theoretical calculation suggests that a different sensitivity for the same SST change with and without the pre-storm RCE adjustment is due to a reduction of $\hat{S}$ [Eq. (5)) sensitivity in RCE.

The first issue in need of discussion is why both $\hat{T}$ and $\hat{S}$ are related to intensity and size. From $V_{\text {pot }}$ theory (Emanuel,
1986, $\hat{T}$ and $\hat{S}$ are two principal factors affecting TC intensity $\hat{T}$ describes the vertical temperature contrast between the sea surface and the outflow layer. Wang et al. (2015) showed that decreasing the temperature in the outflow layer with a fixed SST can increase the TC size, which to some extent shows the linkage between TC size and $\hat{T}$. The factor $\hat{S}$ can be interpreted as the degree of thermodynamic disequilibrium between the air boundary layer and the sea surface, which means $\hat{S}$ is closely related to the enthalpy flux at the sea surface. Xu and Wang (2010) analyzed the contribution of surface enthalpy flux at different radii to TC size. Radu et al. (2014) reported strong sensitivity of TC size to latent heat flux. These studies support the link between TC size and $\hat{S}$.

Although both $\hat{T}$ and $\hat{S}$ can change the TC intensity and size, our results show that only $\hat{S}$ is markedly influenced by RCE adjustments (Table 2). If SST increases without RCE adjustment, the saturation specific humidity at the sea surface increases, whereas the air specific humidity at the reference height remains the same. According to the bulk aerodynamic calculation, the latent heat flux is unrealistically increased. This can lead to considerable increases in intensity, size and hence destructive potential (Table 3). If SST increases and at the same time the environment is adjusted towards RCE, the low-level humidity can be increased via surface evapo- 

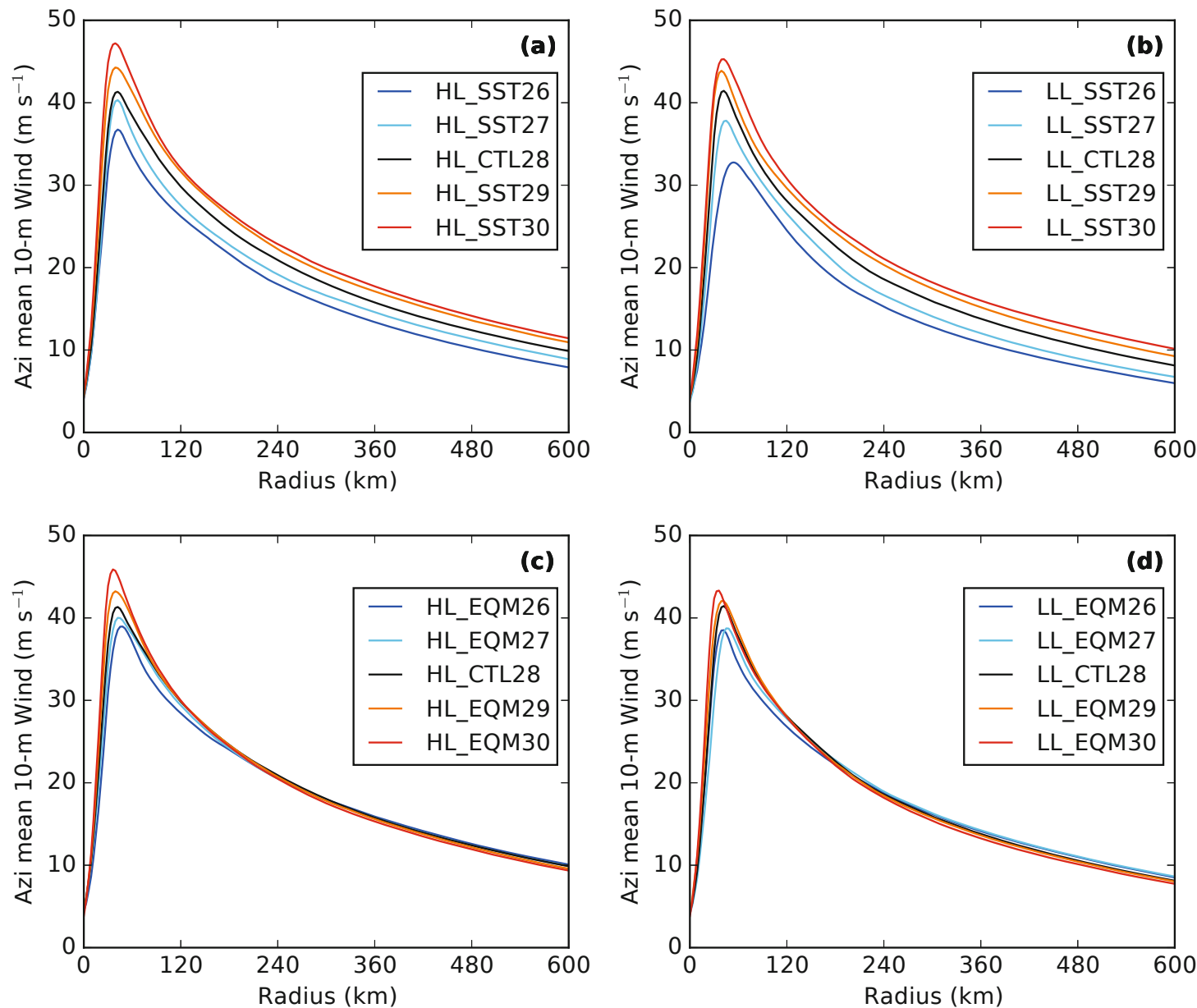

Fig. 5. Azimuthally averaged 10-m wind profile during the mature stage in set (a) HL_SST, (b) LL_SST, (c) HL_EQM and (d) LLEQM.

ration. The specific humidity contrastis then reduced, which results in a weaker enhancement of latent heat flux than the case without RCE adjustment (e.g., Fig. 7b compared with Fig. 7d). However, the change in $T_{\mathrm{s}}$ and $T_{\mathrm{o}}$ due to RCE adjustments is small compared to their base values, so that the ratio of $T_{\mathrm{s}}$ to $T_{\mathrm{o}}$ does not change much. In addition, we find that RCE adjustments usually shift the whole temperature profile towards the same direction with a similar magnitude (e.g., Nolan et al., 2007). Consequently, the change in $\left(T_{\mathrm{S}}-T_{\mathrm{o}}\right)$ due to RCE is also small. All the above changes lead to a high sensitivity of $\hat{S}$ and low sensitivity of $\hat{T}$ with RCE adjustments.

Our simulations are only based on a limited number of runs, but the sensitivity of TC intensity is in line with previous studies. With a future SST field and the present atmospheric state (i.e., an example without the pre-storm RCE adjustment), Lau et al. (2016) showed that the maximum hourly Power Dissipation Index of Hurricane Sandy (2012) can be increased by $100 \%-160 \%$, which corresponds to an increase of about $26 \%-38 \%$ in the surface maximum wind speed. The SST change between present and future states along the track of Hurricane Sandy (2012) in Lau et al. (2016) is about $2^{\circ} \mathrm{C}$.
This simple calculation leads to a sensitivity of intensity to sea surface warming of $15 \%{ }^{\circ} \mathrm{C}^{-1}$. This value is within the range of our theoretical calculation, as shown in Table $3(12 \%$ ${ }^{\circ} \mathrm{C}^{-1}$ in set HL_SST and $17 \%{ }^{\circ} \mathrm{C}^{-1}$ in set LL_SST). As an example with the pre-storm RCE adjustment, Nolan et al. (2007) showed that the sensitivity of intensity to SST changes under RCE is only about $2 \%{ }^{\circ} \mathrm{C}^{-1}$, which is also close to the theoretical and numerical estimations in Table $3\left(2.9 \%{ }^{\circ} \mathrm{C}^{-1}\right.$ to $3.6 \%{ }^{\circ} \mathrm{C}^{-1}$ ).

One may question whether the TC sensitivity with RCE adjustment is more realistic in a warming climate. An SST increase without any RCE adjustment is impossible. The time scale for the large-scale sea surface warming can be decades, and it is much longer than the time scale of RCE, which is of the order of tens of days. However, a perfect RCE may rarely exist in the tropics, because of large-scale circulations (Manabe and Strickler, 1964). As discussed in previous studies (Bretherton et al., 2005; Nolan et al., 2007), the RCE state shares certain features of the tropics but is still idealized. In this regard, our sensitivity experiments with and without the pre-storm RCE adjustments may simulate two extreme situations. To find out which situation is closer to the sensitivity 

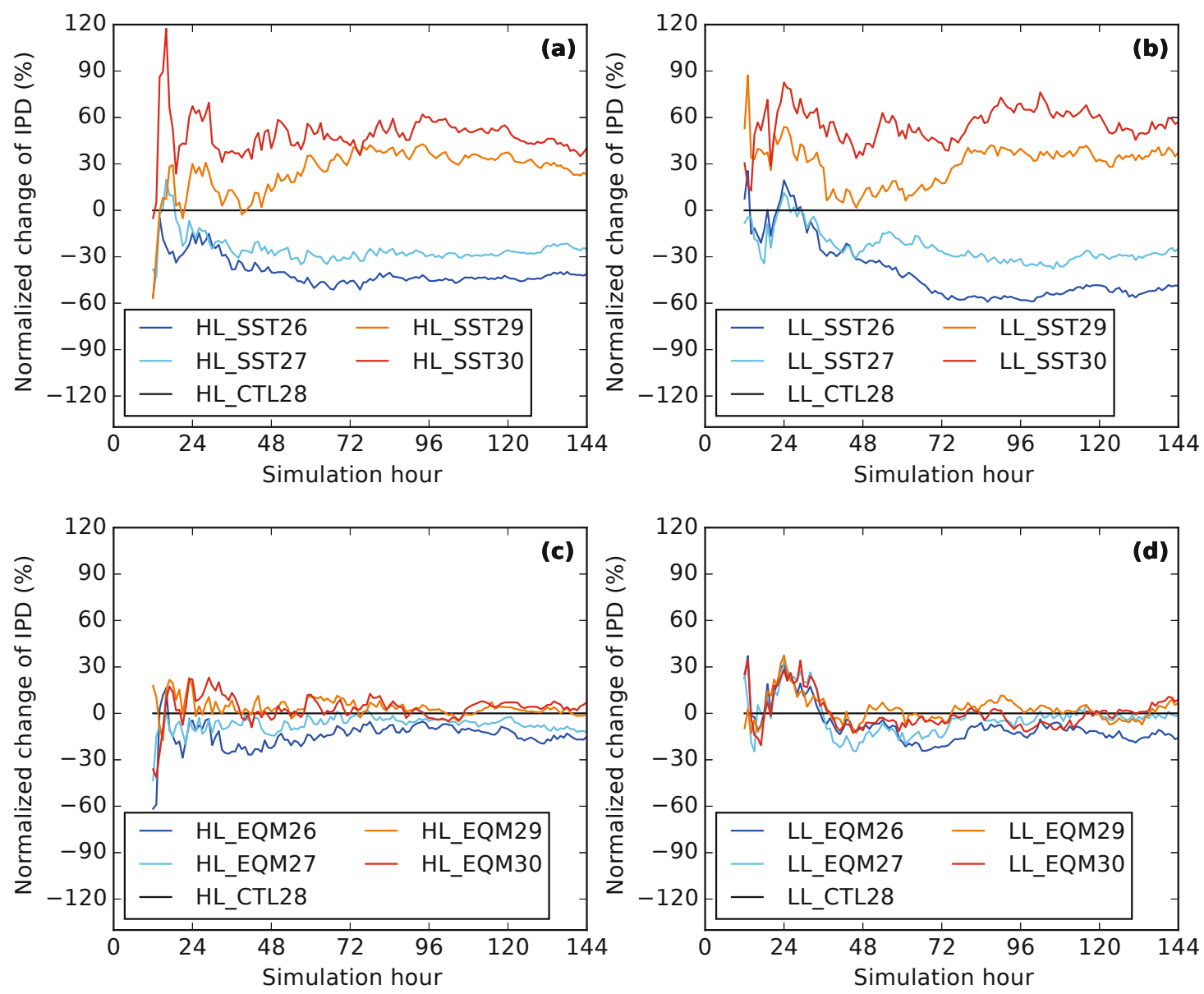

Fig. 6. As in Fig. 3 but for the percentage change (units: \%) of IPD relative to the control runs.

of real TCs in a warming climate, we can compare our results with the predictions by climate models.

By simulating idealized TCs with the atmospheric temperature and moisture profiles and SSTs from coupled climate models, Knutson and Tuleya (2004) found that the maximum surface wind increased by about $6 \%$ as a response to a $1.75^{\circ} \mathrm{C} \mathrm{CO}^{2}$-induced tropical sea surface warming. If we assume the intensity response in their study is also linear, that corresponds to an intensity sensitivity of $3.4 \%{ }^{\circ} \mathrm{C}^{-1}$. Knutson et al. (2015) showed that the sensitivity of TC intensity to sea surface warming is $2.9 \%{ }^{\circ} \mathrm{C}^{-1}, 4.6 \%{ }^{\circ} \mathrm{C}^{-1}$ and $3.5 \%$ ${ }^{\circ} \mathrm{C}^{-1}$ in the North Atlantic, eastern North Pacific and western North Pacific, respectively, with a mean of $3.7 \%{ }^{\circ} \mathrm{C}^{-1}$. A more recent study (Yoshida et al., 2017) found that the lifetime maximum intensity of global TCs may increase by $9 \%$ with an average sea surface warming of $3^{\circ} \mathrm{C}-3.2^{\circ} \mathrm{C}$ in the tropics. Their finding therefore also suggests an intensity sensitivity of about $3 \%{ }^{\circ} \mathrm{C}^{-1}$. The intensity sensitivity found in Knutson and Tuleya (2004), Knutson et al. (2015) and Yoshida et al. (2017) is consistent with our numerical simulations under RCE (Table 3).

This agreement on the intensity sensitivity by climate models and our RCE simulations suggests that the intensity trend in those climate model projections can be considered as largely due to the thermodynamic response in RCE, and thus any changes in large-scale dynamics, such as vertical wind shear, are minor contributors in those climate model projections. Despite this generalization, there could be regional differences, as dynamic factors are important controls on TC intensity and structure. For example, Wang and Toumi (2016) showed that the variation of both IPD and Power Dissipation Index of US landfalling hurricanes can be largely explained by the vertical wind shear in the main genesis area, and Vecchi and Soden (2007) reported a tropical Atlantic wind shear increase in their climate projections.

Regarding the size change, most climate models are unable to project a trend due to low spatial resolution. However, with a coupled dynamical downscaling approach, Knutson et al. (2015) could simulate a reasonable distribution of global $\mathrm{TC}$ size. They found that in a warming future, there will be fewer TCs in total, with a general increase in the lifetime maximum wind, but almost no change in the global mean size. This low sensitivity of TC size to SST change agrees well with our simulations under RCE (Table 3). Furthermore, Emanuel (2005) showed a sharp increase in the Power Dissipation Index of the North Atlantic TCs after 1980 with an increase of SST. However, no similar trend in the observed TC size was found during that period (Knaff et al., 2014). These 


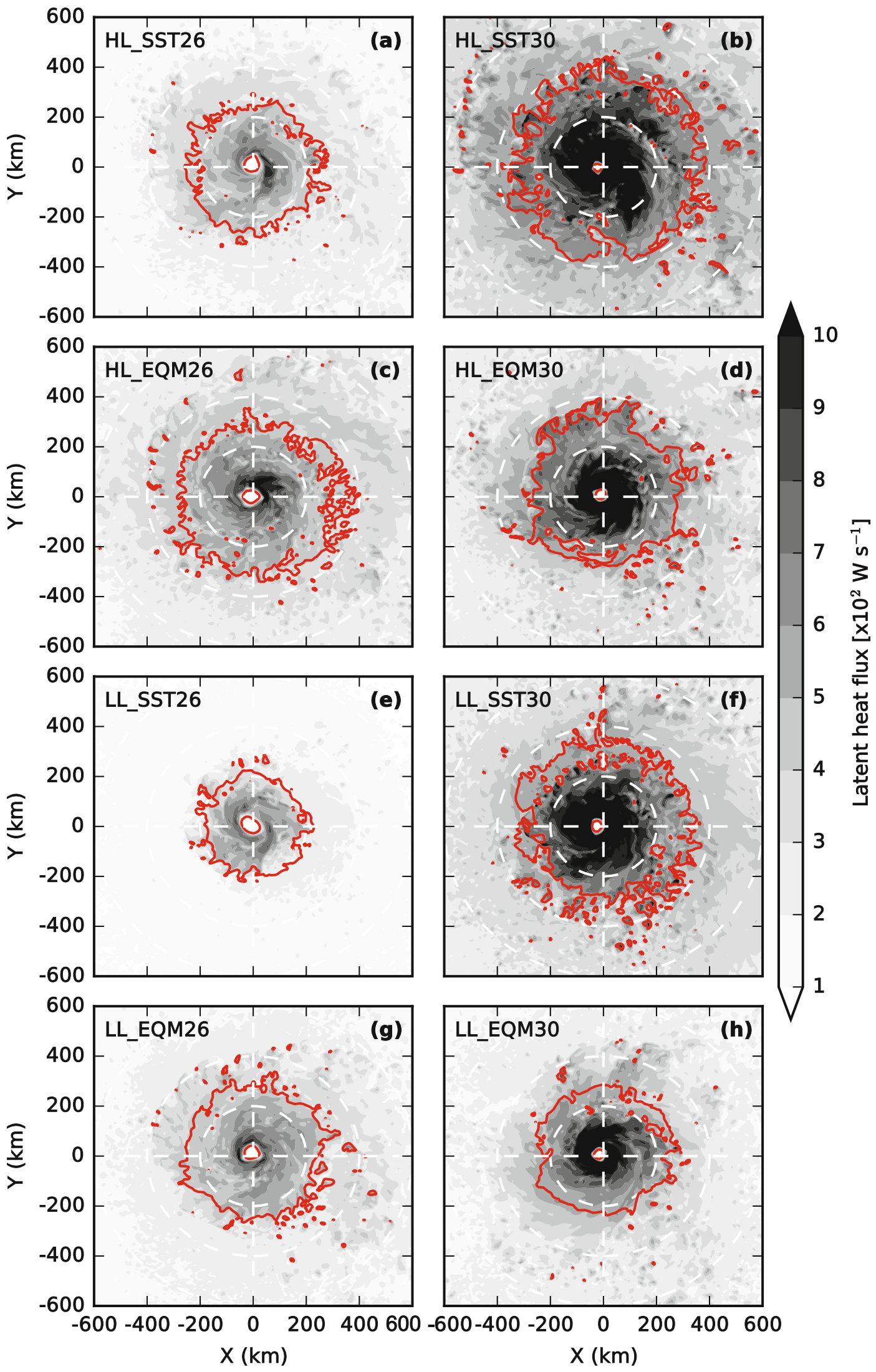

Fig. 7. Latent heat flux (shading; units: $10^{2} \mathrm{~W} \mathrm{~s}^{-1}$ ) at simulation hour 72 in simulation (a) HL_SST26, (b) HL_SST30, (c) HL_EQM26, (d) HL_EQM30, (e) LL_SST26, (f) LL_SST30, (g) LL_EQM26 and (h) LL_EQM30. The red contours show the isotachs of gale-force wind $\left(18 \mathrm{~m} \mathrm{~s}^{-1}\right)$ at a height of $10 \mathrm{~m}$. Three circles (white dashed lines) are placed at radii of 200, 400 and $600 \mathrm{~km}$ from the TC center. 
studies suggest that the response of TC intensity and size to sea surface warming in an idealized RCE environment is in agreement with the coupled climate models and observations.

\section{Conclusions}

In this study we have compared the sensitivities of TC intensity, size and destructive potential to SST changes with and without a pre-storm RCE adjustment. We find that TCs show relatively low sensitivity to sea surface warming under $\mathrm{RCE}$. This is because the RCE adjustment reduces the degree of thermodynamic disequilibrium between the air boundary layer and the sea surface, which leads to less surface latent heat flux than without any RCE adjustment.

We find that the sensitivity of TC intensity is about $3 \%{ }^{\circ} \mathrm{C}^{-1}-4 \%{ }^{\circ} \mathrm{C}^{-1}$ in RCE. Our results also show that the TC size is insensitive to SST change in RCE. As a combined metric of intensity and size, IPD changes are not significant. Without any RCE adjustment, regional TC model studies are likely to show unrealistically large responses to SST perturbations. The sensitivity of TC intensity and size under RCE in our simulations is consistent with projections by climate models. This suggests that first-order projected global changes in TC intensity are driven by thermodynamics not dynamics.

Acknowledgements. This work and its contributors were supported by the UK-China Research \& Innovation Partnership Fund through the Met Office Climate Science for Service Partnership China as part of the Newton Fund. SW was also supported by the National Natural Science Foundation of China (Grant No. 41706007), China Postdoctoral Science Foundation (Grant No. 2017M611960) and the National Programme on Global Change and Air-Sea Interaction (Grant No. GASI-IPOVAI-04).

Open Access This article is distributed under the terms of the Creative Commons Attribution License which permits any use, distribution, and reproduction in any medium, provided the original author(s) and the source are credited.

\section{REFERENCES}

Bender, M. A., T. R. Knutson, R. E. Tuleya, J. J. Sirutis, G. A. Vecchi, S. T. Garner, and I. M. Held, 2010: Modeled impact of anthropogenic warming on the frequency of intense Atlantic hurricanes. Science, 327, 454-458, https://doi.org/10.1126/ science. 1180568.

Bretherton, C. S., P. N. Blossey, and M. Khairoutdinov, 2005: An energy-balance analysis of deep convective self-aggregation above uniform SST. J. Atmos. Sci., 62, 4273-4292, https:// doi.org/10.1175/JAS3614.1.

Chan, J. C. L., 2005: The physics of tropical cyclone motion. Annual Review of Fluid Mechanics, 37, 99-128, https://doi.org/ 10.1146/annurev.fluid.37.061903.175702.

Chan, J. C. L., and R. T. Williams, 1987: Analytical and numerical studies of the beta-effect in tropical cyclone motion. Part I: Zero mean flow. J. Atmos. Sci., 44, 1257-1265, https://doi.
org/10.1175/1520-0469(1987)044<1257:AANSOT>2.0.CO; 2.

Chavas, D. R., and K. Emanuel, 2014: Equilibrium tropical cyclone size in an idealized state of axisymmetric radiativeconvective equilibrium. J. Atmos. Sci., 71, 1663-1680, https:// doi.org/10.1175/JAS-D-13-0155.1.

Courtney, J., and J. A. Knaff, 2009: Adapting the Knaff and Zehr wind-pressure relationship for operational use in Tropical Cyclone Warning Centres. Australian Meteorological and Oceanographic Journal, 58, 167-179, https://doi.org/ 10.22499/2.5803.002.

Dudhia, J., 1989: Numerical study of convection observed during the winter monsoon experiment using a mesoscale twodimensional model. J. Atmos. Sci., 46, 3077-3107, https://doi. org/10.1175/1520-0469(1989)046<3077:NSOCOD>2.0.CO; 2 .

Emanuel, K., 2003: Tropical cyclones. Annual Review of Fluid Mechanics, 31, 75-104, https://doi.org/10.1146/annurev. earth.31.100901.141259.

Emanuel, K., 2005: Increasing destructiveness of tropical cyclones over the past 30 years. Nature, 436, 686-688, https://doi.org/ 10.1038/nature03906.

Emanuel, K., 2007: Environmental factors affecting tropical cyclone power dissipation. J. Climate, 20, 5497-5509, https:// doi.org/10.1175/2007JCLI1571.1.

Emanuel, K. A., 1986: An air-sea interaction theory for tropical cyclones. Part I: Steady-state maintenance. J. Atmos. Sci., 43, 585-605, https://doi.org/10.1175/1520-0469(1986)043 $<0585$ :AASITF $>2.0 . \mathrm{CO} ; 2$.

Emanuel, K. A., 1991: The theory of hurricanes. Annual Review of Fluid Mechanics, 23, 179-176, https://doi.org/10.1146/ annurev.fl.23.010191.001143.

Emanuel, K. A., 1995: Sensitivity of tropical cyclones to surface exchange coefficients and a revised steady-state model incorporating eye dynamics. J. Atmos. Sci., 52, 3969-3976, https:// doi.org/10.1175/1520-0469(1995)052<3969: SOTCTS $>2.0$. $\mathrm{CO} ; 2$.

Emanuel, K. A., 1999a: Thermodynamic control of hurricane intensity. Nature, 401, 665-669, https://doi.org/10.1038/44326.

Emanuel, K. A., 1999b: The power of a hurricane: An example of reckless driving on the information superhighway. Weather, 54, 107-108, https://doi.org/10.1002/j.1477-8696. 1999.tb06435.x.

Holland, G. J., 1997: The maximum potential intensity of tropical cyclones. J. Atmos. Sci., 54, 2519-2541, https://doi.org/ 10.1175/1520-0469(1997)054<2519:TMPIOT>2.0.CO;2.

Hong, S.-Y., and J.-O. J. Lim, 2006: The WRF Single-Moment 6class microphysics scheme (WSM6). Asia-Pacific Journal of Atmospheric Sciences, 42, 129-151.

Jordan, C. L., 1958: Mean soundings for the West Indies Area. J. Meteor., 15, 91-97, https://doi.org/10.1175/1520-0469(1958) 015<0091:MSFTWI>2.0.CO;2.

Knaff, J. A., and R. M. Zehr, 2007: Reexamination of tropical cyclone wind-pressure relationships. Wea. Forecasting, 22, 7188, https://doi.org/10.1175/WAF965.1.

Knaff, J. A., S. P. Longmore, and D. A. Molenar, 2014: An objective satellite-based tropical cyclone size climatology. J. Climate, 27, 455-476, https://doi.org/10.1175/JCLI-D-1300096.1.

Knutson, T. R., and R. E. Tuleya, 2004: Impact of $\mathrm{CO}_{2}$-induced warming on simulated hurricane intensity and precipitation: Sensitivity to the choice of climate model and convective 
parameterization. J. Climate, 17, 3477-3495, https://doi.org/ 10.1175/1520-0442(2004)017<3477:IOCWOS>2.0.CO;2.

Knutson, T. R., J. J. Sirutis, M. Zhao, R. E. Tuleya, M. Bender, G. A. Vecchi, G. Villarini, and D. Chavas, 2015: Global projections of intense tropical cyclone activity for the late twenty-first century from dynamical downscaling of CMIP5/RCP4.5 scenarios. J. Climate, 28, 7203-7224, https:// doi.org/10.1175/JCLI-D-15-0129.1.

Knutson, T. R., and Coauthors, 2010: Tropical cyclones and climate change. Nature Geoscience, 3, 157-163, https://doi.org/ 10.1038/ngeo779.

Large, W. G., and S. G. Yeager, 2008: The global climatology of an interannually varying Air-sea flux data set. Climate Dyn., 33, 341-364, https://doi.org/10.1007/s00382-008-0441-3.

Lau, W. K. M., J. J. Shi, W. K. Tao, and K. M. Kim, 2016: What would happen to Superstorm Sandy under the influence of a substantially warmer Atlantic Ocean? Geophys. Res. Lett., 43, 802-811, https://doi.org/10.1002/2015GL067050.

Manabe, S., and R. F. Strickler, 1964: Thermal equilibrium of the atmosphere with a convective adjustment. J. Atmos. Sci., 21, 361-385, https://doi.org/10.1175/1520-0469(1964)021 $<0361$ :TEOTAW $>2.0$. CO;2.

Mlawer, E. J., S. J. Taubman, P. D. Brown, M. J. Iacono, and S. A. Clough, 1997: Radiative transfer for inhomogeneous atmospheres: RRTM, a validated correlated-k model for the longwave. J. Geophys. Res., 102, 16 663-16 682, https://doi.org/ 10.1029/97JD00237.

Montgomery, M. T., and R. K. Smith, 2017: Recent developments in the fluid dynamics of tropical cyclones. Annual Review of Fluid Mechanics, 49, 541-574, https://doi.org/10.1146/ annurev-fluid-010816-060022.

Nolan, D. S., E. D. Rappin, and K. A. Emanuel, 2007: Tropical cyclogenesis sensitivity to environmental parameters in radiative-convective equilibrium. Quart. J. Roy. Meteor. Soc., 133, 2085-2107, https://doi.org/10.1002/qj.170.

Radu, R., R. Toumi, and J. Phau, 2014: Influence of atmospheric and sea surface temperature on the size of hurricane Catarina. Quart. J. Roy. Meteor. Soc., 140, 1778-1784, https://doi.org/ 10.1002/qj.2232.

Skamarock, W. C., and Coauthors, 2008: A description of the advanced research WRF version 3. NCAR Tech. Note NCAR/ TN-475+STR, 113 pp, https://doi.org/10.5065/D68S4MVH.

Sun, Y., and Coauthors, 2017: Impact of ocean warming on tropi- cal cyclone size and its destructiveness. Scientific Reports, 7, 8154, https://doi.org/10.1038/s41598-017-08533-6.

Tompkins, A. M., and G. C. Craig, 1998a: Radiative-convective equilibrium in a three-dimensional cloud-ensemble model. Quart. J. Roy. Meteor. Soc., 124, 2073-2097, https://doi.org/ 10.1002/qj.49712455013.

Tompkins, A. M., and G. C. Craig, 1998b: Time-scales of adjustment to radiative-convective equilibrium in the tropical atmosphere. Quart. J. Roy. Meteor. Soc., 124, 2693-2713, https:// doi.org/10.1002/qj.49712455208.

Vecchi, G. A., and B. J. Soden, 2007: Increased tropical Atlantic wind shear in model projections of global warming. Geophys. Res. Lett., 34, L08702, https://doi.org/10.1029/2006 GL028905.

Vecchi, G. A., K. L. Swanson, and B. J. Soden, 2008: Whither hurricane activity? Science, 322, 687-689, https://doi.org/ 10.1126/science. 1164396 .

Walsh, K. J. E., and Coauthors, 2016: Tropical cyclones and climate change. Wiley Interdisciplinary Reviews: Climate Change, 7, 65-89, https://doi.org/10.1002/wcc.371.

Wang, S., and R. Toumi, 2016: On the relationship between hurricane cost and the integrated wind profile. Environmental Research Letters, 11, 114005, https://doi.org/10.1088/17489326/11/11/114005.

Wang, S., and R. Toumi, 2017: A historical analysis of the mature stage of tropical cyclones. International Journal of Climatology, https://doi.org/10.1002/joc.5374. (in press)

Wang, S., R. Toumi, A. Czaja, and A. Van Kan, 2015: An analytic model of tropical cyclone wind profiles. Quart. J. Roy. Me teor. Soc., 141, 3018-3029, https://doi.org/10.1002/qj.2586.

Xu, J., and Y. Q. Wang, 2010: Sensitivity of tropical cyclone innercore size and intensity to the radial distribution of surface entropy flux. J. Atmos. Sci., 67, 1831-1852, https://doi.org/ 10.1175/2010JAS3387.1.

Yoshida, K., M. Sugi, R. Mizuta, H. Murakami, and M. Ishii, 2017: Future changes in tropical cyclone activity in high-resolution large-ensemble simulations. Geophys. Res. Lett., 44, 9910 9917, https://doi.org/10.1002/2017GL075058.

Zhang, D. L., and R. A. Anthes, 1982: A high-resolution model of the planetary boundary layer-sensitivity tests and comparisons with SESAME-79 data. J. Appl. Meteor., 21, 1594-1609, https://doi.org/10.1175/1520-0450(1982)021 $<1594$ :AHRMOT>2.0.CO;2. 